\title{
Comparison of coverage with insecticide-treated nets in a Tanzanian town and villages where nets and insecticide are either marketed or provided free of charge
}

\author{
CA Maxwell1,2, RT Rwegoshora ${ }^{2}$, SM Magesa ${ }^{2}$ and CF Curtis*1
}

\author{
Address: ${ }^{1}$ London School of Hygiene \& Tropical Medicine, London WC1E 7HT, UK and ${ }^{2}$ National Institute for Medical Research, Amani Medical \\ Research Centre, Box 81, Muheza, Tanzania \\ Email: CA Maxwell - cmaxwell@nimr.or.tz; RT Rwegoshora - theophilr@hotmail.com; SM Magesa - smagesa@hotmail.com; \\ CF Curtis* - chris.curtis@lshtm.ac.uk \\ * Corresponding author
}

Published: 21 May 2006

Malaria Journal 2006, 5:44 doi:10.1186/1475-2875-5-44

This article is available from: http://www.malariajournal.com/content/5///44

(c) 2006 Maxwell et al; licensee BioMed Central Ltd.

This is an Open Access article distributed under the terms of the Creative Commons Attribution License (http://creativecommons.org/licenses/by/2.0), which permits unrestricted use, distribution, and reproduction in any medium, provided the original work is properly cited.
Received: 20 January 2006

Accepted: 21 May 2006

\begin{abstract}
Background: There is much emphasis on social marketing as a means of scaling up coverage with insecticide-treated nets and the question has arisen whether nets provided free-of-charge will be looked after by householders.
\end{abstract}

Methods: Over several years questionnaires and surveys of usage and condition of nets were carried out throughout a town and 15 villages in north-east Tanzania, where nets and insecticide have to be purchased and in 24 other villages where over 15000 nets had been donated and annual re-treatment is provided free-of-charge.

Results: There was very high population coverage in the town but, in the villages where nets have to be purchased, only $9.3 \%$ of people used nets which were intact and/or had been insecticidetreated and could, therefore, provide protection. However, where nets had been provided free, over $90 \%$ of the nets were still present and were brought for re-treatment several years later.

Conclusion: In this part of Tanzania, social marketing has performed well in a town but very poorly in villages. However, the study showed that people look after and bring for re-treatment nets which had been provided free-of-charge.

\section{Background}

Bednets provide no protection if torn and untreated but, if intact and/or insecticidal, nets provide good, but not perfect, personal protection to sleepers against night biting mosquitoes [1-3]. If used by almost all members of a community, insecticidal nets kill large numbers of the local malaria vectors, reducing the mean survival, sporozoite rate and population density of the vector population and hence substantially reducing its entomological inoculation rate (EIR) [4]. This "bonus" effect of community- wide coverage of insecticide treated nets (ITNs) can equal or exceed the personal protection effect $[5,6]$.

Especially in Tanzania, there has been much emphasis on scaling up coverage with ITNs via social marketing and, comparing households who were able and willing to purchase nets with those who were not, there was significantly less child mortality and malaria morbidity in the former $[7,8]$. The argument advanced in favour of social marketing is that sustained donor funding to provide ITNs 
free of charge cannot be relied upon. It is therefore considered preferable to use existing donor funding to subsidize schemes which use advertising to encourage householders to become accustomed to spending their own money to buy nets and insecticide.

In assessing whether marketing schemes are well targeted and effective nationwide it is necessary to take account of the marked social and entomological heterogeneities between urban and rural areas. In the former, most households are supported by wage earners and people are much troubled by the nuisance biting of Culex mosquitoes which breed in organically polluted water in pit latrines, cess pits and open drains. There are generally few breeding sites suitable for Anopheles and malaria transmission is much lower in long established and densely populated urban areas, in contrast to nearby rural or semi-rural areas [9]. In African villages many households are subsistence farmers with relatively little involvement in a cash economy and the ground water is generally clean enough for the breeding of large numbers of Anopheles gambiae s.l.. and Anopheles funestus. Therefore, these communities suffer the majority of Africa's and the world's malaria burden.

In assessing the cost to donors of a sustained scheme for free provision of ITNs it is necessary to assess how well donated nets are looked and after how many years nets would have to be replaced because they have become so torn that householders discard them Hitherto there has been little data available on these factors.

\section{Methods and materials}

In the course of censuses in 2001-2005, in preparation for proposed future multi-village trials with ITNs, all householders were questioned in 15 villages in Muheza district, north east Tanzania, about which members of the family used nets and whether they had been insecticide-treated. In total, data were collected on net usage by 16683 people. The nets were also inspected to determine whether they were intact or holed, according to the definition of Maxwell et al [10]. In 2004, all houses in Muheza town were censused and householders were questioned about the total numbers of nets owned by the household and whether they had been treated. Data were collected on net usage by 4373 people. These urban nets were not inspected for damage, because the townspeople were less tolerant of intrusion into their houses than were the villagers. Thirdly, in 2001-2004 villages were re-visited in which, as far as possible, every sleeping place in every house had been provided with an indelibly numbered ITN free of charge against a householder's signature. The nets provided were made of 70 denier fibre. The distributions had been in the course of trials in eight lowland (altitude about $200 \mathrm{~m}$ ) villages which started in 1995-6 $[5,10]$ and 10 lowland and 11 highland (altitude approximately $1,000 \mathrm{~m}$ ) villages starting in 2000 [6]. The total numbers of nets which had originally been provided in these three sets of villages were over 15000 . Records were kept of nets being brought for the annual re-treatment, which is provided by a supervisor, visiting by motorcycle and bringing free insecticide. The nets being brought by each householder were matched with records of those previously given to that household, noting nets which had gone missing and recording the number of the nets which were intact or holed, as defined by Maxwell et al [10]. In some cases it was possible to repeat surveys in the same villages at different times after provision of nets but in other cases the surveys were in different villages in which human behaviour regarding their nets may vary somewhat. This was probably the reason for some apparently anomalous results such as somewhat more nets being recorded as intact after $6-7$ years than after 5-6 years.

\section{Results and discussion}

Table 1 shows that in Muheza town 93.2\% of households had bought at least some nets and the total number of nets was about $50 \%$ of the human population revealed by our census, implying very high coverage of the population by nets, considering that many of the nets would be used by two or more people. It was reported that $27.2 \%$ of nets were insecticidal, i.e. had been treated at some time with an Ngao insecticide sachet (or in a few cases there were Permanet $^{\circledast}$ Long Lasting Insecticidal nets). The high net usage can mainly be attributed to a desire to avoid Culex nuisance biting and to response to advertising (urban billboards etc) organized by the Social Marketing campaign and net manufacturers. Appreciable numbers of Anopheles probably fly into a small town like Muheza from nearby semi-rural breeding sites and the nets presumably serve a useful anti-malaria function. The insecticide sachets are advertised in the town but uptake was not as good as for nets. The treated nets would have given personal protec-

Table I: Data on the households in Muheza town

No. people surveyed by questionnaire:

No. nets in their houses

$\%$ of households reported to be using nets

$\%$ of nets treated with Ngao insecticide sachets (+Permanets)

$\%$ of nets rectangular (not conical)
4373

\author{
2197 (approx. 0.5× no. people) \\ 93.2\% (data on 948 households) \\ 26.3\% Ngao; $0.9 \%$ Permanets (data on 2197 nets) \\ $45.6 \%$ (data on 2197 nets)
}


Table 2: Data from censuses of 15 villages where nets and insecticide have to be bought

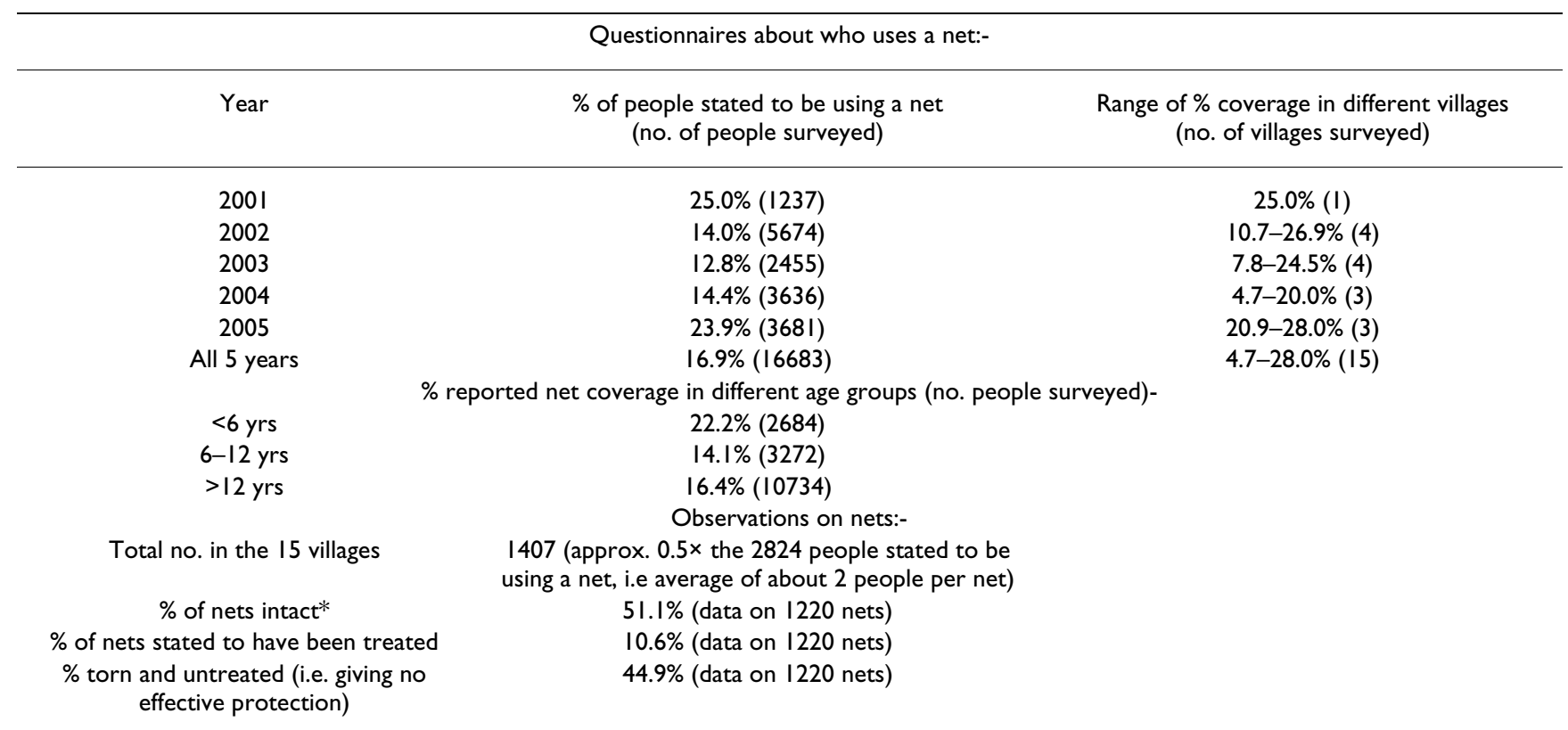

* by definition of Maxwell et al [10]

tion even if holed. However, when only about a quarter of net encounters by Anopheles would lead to a risk of mortality, any consequent reduction in EIR of the local vector population would be far less than the EIR reductions observed when ITN coverage is so high that almost every net encounter by an Anopheles mosquito has a high probability of killing it. [4,6]. About half of the nets were of the conical type, with which it is rather difficult for a sleeper to avoid skin contact and there is some evidence [2] that these nets are not so effective as rectangular nets in preventing mosquitoes biting through nets.

Table 2 shows that, compared with the urban data, there was an entirely different picture in those surveyed villages in which (as in the town) netting and insecticide had to be purchased by householders. The percentage of people reported to be using a net varied between villages but averaged only $16.9 \%$ over all age groups, with a somewhat higher rate among young children (who are the most vulnerable to malaria) and a somewhat lower rate among older children. The 2,824 people reported to be using a net and the total of 1,407 nets recorded imply a mean of 2.0 people per net (appreciably more than the mean of 1.7 found by Curtis et al [11]. There was no sign of a hopedfor upward trend in net usage over the years 2001-2005 as the social marketing programme developed and supposedly became nationwide in Tanzania. Inspections showed that only $51.1 \%$ of nets were intact and $10.6 \%$ of nets were reported to have been treated. $44.9 \%$ of nets were holed and untreated and therefore gave no protection; thus, only $9.3 \%$ of the population received any pro- tection by nets from the intense malaria transmission in these villages.

Table 3 shows that, for several years after provision of free nets in villages, about $90 \%$ were still in the households to which they were given and were brought for the annual retreatment. In later years, in the lowlands, the retention of nets declined markedly. This was associated with decrease in the percentage of nets still intact. This indicates that householders understandably did not retain nets when they were so badly holed as to be obviously useless. After about 5 years the condition of the nets was markedly better in the highlands than the lowlands, presumably because in the cool season in the highlands there are few nuisance mosquitoes and many nets are not used and are, therefore, not exposed to wear and tear at that season. In the earlier years in the lowlands and highlands the mean numbers of nets per household were 1.9 and 2.3, respectively, with 4 or more in some households with many children.

It might be thought that provision of free nets to some villages in Muheza district would be well known to people in other villages and to have deterred sales there, as the inhabitants might have expected that eventually free nets would be given to them also. However, many lengthy conversations in the ki-Swahili language showed that in fact people in villages which had not been provided with free nets were not aware of the good fortune of the people in some other villages several kilometres away. It might also be supposed that the people in the "free net" project vil- 
lages were under close supervision of project staff and, therefore, used and treated nets in a way quite atypical of what would happen if large scale free provision became a routine. However, with a team of only five field personnel involved in a number of different projects, contacts with villagers since malaria morbidity surveys were finished some years ago were virtually limited to the annual two to three days of net re-treatment in each of the villages when a technician visits to bring insecticide and supervises the re-treatment process. Such visits involve helpful contact and conversation about ITNs for malaria control and would be expected in a region-wide re-treatment programme, as exists in Vietnam where the nets of 10 million people are re-treated annually (see data of Tran Duc Hinh reproduced in [12]). Such a re-treatment scheme would become unnecessary if there was a complete switch over to use of long-lasting insecticidal nets. Such a switch over could be decided upon by a donor, based on evidence that it would be more cost effective over a four [13] or perhaps a seven-year period [14] to pay more for a long-lasting insecticidal net so as to avoid the expense of annual retreatment. However, where a free market prevails it seems likely that many low income households would go for the net with the cheapest price tag, even if it would be wiser in the long run to invest in a more expensive long lasting insecticidal net. As shown in Table 1, less than $1 \%$ of the Muheza urban households had bought such long lasting nets.

In attempting to market nets to very poor people, much effort and expenditure is required on promotion. However, experience in this part of Tanzania shows that villagers are well aware of bednets and their benefits and the only problem about acquiring nets is finding the money to pay for them. If news is passed through the village authorities that the numbers and sizes of beds would be observed and appropriate ITNs provided free of charge on a certain day, virtually every household is waiting to enthusiastically receive and use these nets.

The estimates of Curtis et al [15] about the annual cost of continent-wide free provision of nets only considered rural populations because these bear the main burden of malaria. Furthermore it was surmised that marketing would work well in towns; this is confirmed by the data in Table 1. Higher altitudes with very low malaria transmission could also be excluded from schemes for free provision, but excellent impact of ITN provision on malaria morbidity at about $1,000 \mathrm{~m} \mathrm{[6]} \mathrm{suggests} \mathrm{that} \mathrm{the} \mathrm{cut-off}$ altitude should be set somewhat higher than that. The above mentioned estimates [15] assumed that polyester nets would become so badly torn after about 4 years that they ought to be replaced then. The data in Table 3 confirm this for lowland villages, but it appears that for cooler highland areas less frequent replacement of nets would be acceptable. It is regrettable that, for the lowland villages referred to in Table 3, there was delay in finding the funding to replace the damaged nets. However, the nets have now been replaced in many of these villages in setting up a comparative trial of different types of long lasting insecticidal net. Worn out ITNs are being replaced in other villages through the generosity of Rotary Clubs.

The data in Table 3, showing the encouraging extent to which nets provided free of charge are retained and looked after, come from annual visits by a re-treatment supervisor to 24 villages. Now that millions of nets are being provided free-of-charge, for example in Eritrea, Togo and Niger, it will be important in the next few years to check whether or not our data based on 24 villages gave reliable indications of the long term retention and condition of nets in region- or nation-wide schemes.

In the Kilombero valley of Tanzania, where social marketing was initiated several years ago, surveys[16] found that a large proportion of the nets were badly torn and untreated with insecticide (and, therefore, unprotective) as was also found in the present study (Table 2). It is understood that some other net surveys in Tanzania have shown better coverage with ITNs in some rural areas and it will be important to determine whether the very poor results of marketing in villages shown in Table 2 are, or are not, typical. In making national assessments it is very important to be sure that samples are not biased in favour of easier-to-reach urbanized areas which may well have a quite atypically high net coverage (Table 1 ). In view of the mean of about 2 nets per household which was found where nets had earlier been provided free of charge, it should be noted that expressing national survey results as percentage of houses with at least one net could give a misleading impression of whether adequate coverage was being achieved.

The introduction of a voucher scheme to enable women attending ante-natal clinics to purchase nets at a subsidized price and linkage of provision of free ITNs to attendance of children at measles vaccination campaigns [17] will hopefully greatly improve rates of personal protection of the most malaria vulnerable members of the population. However, it is doubtful whether these welcome efforts will achieve the full potential of the ITN method for those vulnerable people, which requires coverage of as many as possible of beds in the community with insecticidal nets, so as to maximize mosquito mortality.

\section{Competing interests}

The author(s) declare that they have no competing interests. 
Table 3: Data from surveys of nets still in houses and/or brought for re-treatment and \% still intact in lowland (c.200 $\mathrm{m}$ ) and highland $(c .1000 \mathrm{~m})$ villages where 70 denier nets had been provided free of charge for every bed several years before the surveys, and where re-treatment is provided annually

Lowland

Highland

Nos. of years after nets were provided:-

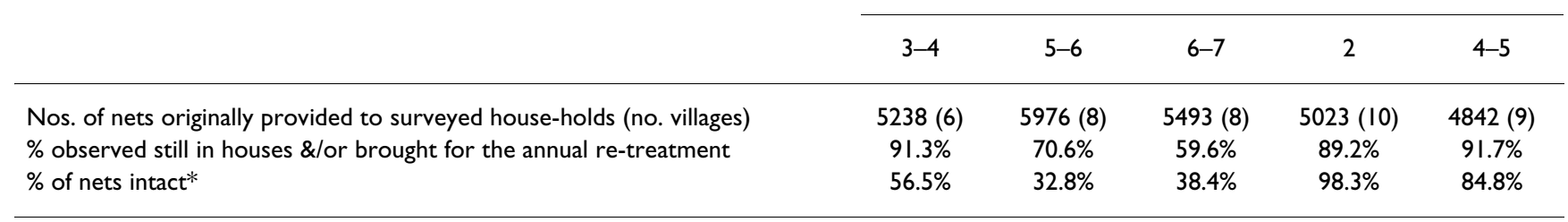

*by definition of Maxwell et al [10]

\section{Authors' contributions}

CAM, TR and SMM organised data collection and entry of it into a computer and they read and approved the manuscript. CFC analysed the data and drafted the manuscript.

\section{Acknowledgements}

We thank the householders who cheerfully tolerated our rather intrusive questions and net inspections. We acknowledge the conscientious work of our field and data entry teams and financial support from the British Medical Research Council.

Clearance for the work and this publication was granted by the Director General of the National Institute for Medical Research, Tanzania.

\section{References}

I. Lines JD, Myamba J, Curtis CF: Experimental hut trials of permethrin impregnated mosquito nets and eave curtains against malaria vectors in Tanzania. Med Vet Ent 1987, I:37-5 I.

2. Curtis CF, Myamba J, Wilkes TJ: Comparison of different insecticides and fabrics for anti-mosquito bednets and curtains. Med Vet Ent 1996, 10:I-II.

3. Soremekun S, Maxwell CA, Zuwakuo M, Chen C, Michael E, Curtis CF: Measuring the efficacy of insecticide treated bednets: the use of DNA fingerprinting to increase the accuracy of personal protection estimates in Tanzania. Trop Med Int Health 2004, 9:664-672

4. Magesa SM, Wilkes TJ, Mnzava AEP, Njunwa KJ, Myamba J, Kivuyo MDP, Hill N, Lines JD, Curtis CF: Trial of pyrethroid impregnated bednets in an area of Tanzania holoendemic for malaria, part 2: Effects on the malaria vector population. Acta Trop 1991, 49:97-108.

5. Maxwell CA, Myamba J, Njunwa KJ, Greenwood BM, Curtis CF: Comparisons of bednets impregnated with different pyrethroids for their impact on mosquitoes and on re-infection with malaria after clearance of existing infections with chlorproguanil-dapsone. Trans R Soc Trop Med Hyg 1999, 93:4-II.

6. Maxwell CA, Chambo W, Mwaimu M, Magogo F, Carneiro IA, Curtis CF: Variations in malaria transmission and morbidity with altitude in Tanzania and with introduction of alphacypermethrin treated nets. Malar J 2003, 2:28.

7. Schellenberg JR, Abdulla $S$, Nathan R, Mukasa $O$, Marchant TJ, Kikumbih N, Mushi AK, Mponda H, Minja H, Mshinda H, Tanner M, Lengeler C: Effect of large scale social-marketing of insecticide-treated nets on child survival in rural Tanzania. Lancet 200I, 337: I24I-1247.

8. Magesa SM, Lengeler C, de Savigny D, Miller JE, Njau RJA, Kramer K, Kitua A, Mwita A: Creating an "enabling environment" for taking insecticide treated nets to national scale: the Tanzanian experience. Malar J 2005, 4:34.
9. Trape JF, Zoulani A: Malaria and urbanization in Central Africa: the example of Brazzaville: III. Relationships between urbanization and the intensity of malaria transmission. Trans $R$ Soc Trop Med Hyg 1987, 8 I (suppl 2): 19-25.

10. Maxwell CA, Msuya E, Sudi M, Njunwa KJ, Carneiro IA, Curtis CF: Effect on malaria morbidity of community-wide use in Tanzania of insecticide treated nets for 3-4 years. Trop Med Int Health 2002, 7:1003-1008.

II. Curtis CF, Maxwell CA, Finch RJ, Njunwa KJ: A comparison of use of a pyrethroid either for house spraying or for bednet treatment against malaria vectors. Trop Med Int Health 1998, 3:619-631.

12. Curtis CF, Jana-Kara B, Maxwell CA: Insecticide treated nets: impact on vector populations and relevance of initial intensity of transmission and pyrethroid resistance. J Vector Borne Diseases 2003, 40:I-8.

13. Maxwell CA, Myamba J, Magoma J, Rwegoshora RT, Magesa SM, Curtis CF: Tests of Olyset nets by bioassay and in experimental huts. J Vector Borne Diseases 2006, 43: I-6.

14. Tami A, Mubyazi G, Talbert A, Mshinda H, Duchon S, Lengeler C Evaluation of Olyset insecticide-treated nets distributed seven years ago in Tanzania. Malar J 2004, 3:1-9.

15. Curtis CF, Maxwell C, Lemnge M, Kilama WL, Steketee RW, Hawley WA, Bergevin Y, Campbell CC, Sachs J, Teklehaimanot A, Ochola S, Guyatt $H$, Snow RW: Scaling-up coverage with insecticidetreated nets against malaria in Africa: who should pay? Lancet Inf Dis 2003, 3:304-307.

16. Erlanger TE, Enyati AA, Hemingway J, Mshinda H, Tami A, Lengeler $\mathrm{C}$ : Field issues related to effectiveness of insecticide-treated nets in Tanzania. Med Vet Ent 2004, 18:153-160.

17. Grabowsky M, Farrell N, Hawley W, Chimumbwa J, Hoyer S, Wolkon A, Selaniko J: Integrating insecticide-treated bednets into measles vaccination campaign achieves high, rapid and equitable coverage with direct and voucher-based methods. Trop Med Int Health 2005, 10: I I5I-I I60.

Publish with Bio Med Central and every scientist can read your work free of charge

"BioMed Central will be the most significant development for disseminating the results of biomedical research in our lifetime. "

Sir Paul Nurse, Cancer Research UK

Your research papers will be:

- available free of charge to the entire biomedical community

- peer reviewed and published immediately upon acceptance

- cited in PubMed and archived on PubMed Central

- yours - you keep the copyright 
